\title{
Desenvolvimento escolar e abuso de drogas na adolescência'
}

\author{
School development and adolescents' drug abuse
}

\author{
Flávia Rocha Campos BAHLS² \\ Yara Kuperstein INGBERMANN ${ }^{3}$
}

\begin{abstract}
Resumo
O objetivo da presente pesquisa foi investigar a história escolar de adolescentes internados para tratamento por uso de drogas, a partir de informações contidas em suas autobiografias. A análise baseou-se em autobiografias de treze moças e de quinze rapazes. Os conteúdos da categoria"história escolar"foram analisados e os dados encontrados são apresentados em quadros com suas respectivas subcategorias. Encontrou-se que o grau de escolaridade das moças era maior em relação ao dos rapazes, e menores os índices de reprovação e expulsão; já os rapazes, desde muito cedo, iniciaram uma trajetória escolar com dificuldades e abandono da escola. Os achados sugerem que fatores escolares podem prenunciar o abuso de drogas na adolescência. Tal compreensão oferece uma chance para nortear abordagens preventivas.
\end{abstract}

Palavras-chave: abuso de drogas; adolescência; desenvolvimento escolar; gênero.

\begin{abstract}
This study purpose was the previous school development investigation of adolescents who were under a psychoactive substance abuse treatment. The investigation was based on the analysis of adolescent's written reports content. There were 13 female adolescents' written reports available, and fifteen male ones. The content of school previous performance category were evaluated, and its data are exposed with the appropriate sub-categories. According to the results, there is a low frequency of school disabilities and also a good school performance among girls, while boys have presented early disabilities and bad performance at school. This study suggests that school-related factors may predict adolescent's drug abuse and gender differences. This knowledge can be used on preventive programs development.
\end{abstract}

Key words: drug abuse; adolescence; school performance; gender.

Dentre os fatores de risco associados ao abuso de drogas e sintetizados pelo National Institute on Drug Abuse dos Estados Unidos da América (National Institute on Drug, 1997), encontram-se os ligados à socialização, que dizem respeito à interação da criança com os agentes socializadores fora da família, especificamente a escola, os pares e a comunidade. Os fatores de risco ligados à socialização são: (a) comportamento agressivo e inapropriado em sala de aula, (b) fracasso no desempenho escolar, (c) habilidades sociais

1 Artigo elaborado a partir da dissertação de F.R.C. BAHLS, intitulada "Análise de auto-relatos de adolescentes internados pelo uso de substâncias psicoativas". Universidade Federal do Paraná. Curitiba.

2 Universidade Tuiuti do Paraná. Rua Carneiro Lobo, 570, conjunto 1403, Curitiba, PR, Brasil. Correspondência para/Correspondence to F.R.C. BAHLS. E-mail:<fbahls@superig.com.br>.

3 Programa de Pós-Graduação em Psicologia, Universidade Federal do Paraná e do Curso de Psicologia, Centro Universitário Positivo. Curitiba, PR, Brasil. 
empobrecidas, (d) afiliação com pares que apresentam comportamentos desviantes e (e) percepção de que na escola, entre os pares e na comunidade existe aprovação do comportamento de uso de drogas.

Os fatores protetores não são sempre opostos aos fatores de risco, e dentre os principais fatores de proteção, incluem-se o sucesso no desempenho escolar e os vínculos fortes com instituições pró-sociais, como a escola (National Institute on Drug, 1997).

O uso de substâncias estabelecido entre os $14 \mathrm{e}$ 15 anos de idade pode ser prenunciado pelo comportamento social e escolar demonstrado entre os 7 e os 9 anos de idade. Em estudo longitudinal, Hops, Davis e Lewin (1999) avaliaram 365 crianças, entre seus sete e quinze anos de idade, quanto às habilidades escolares e sociais, e quanto ao ambiente em casa. Encontraram que quanto maiores as dificuldades escolares e sociais na escola elementar - correspondente ao nosso ensino fundamental -, mais as crianças entraram num continuum de uso de drogas estabelecido na pesquisa: só uso de álcool, só álcool e tabaco, ou álcool, tabaco e maconha e outras drogas. Para as meninas o ambiente em casa moderou o efeito das variáveis escolares e sociais.

O baixo desempenho escolar em estudantes pode excluí-los, em algum grau, do grupo de estudantes que têm mais sucesso, levando-os ao envolvimento com pares que apresentem problemas em aspectos escolares. O impacto do grupo de pares é um fator que interfere no uso de substâncias, e os autores evidenciam que quanto maior a associação com pares desviantes maior a probabilidade de desvio e uso de drogas (Kumpulainem \& Roine, 2002).

Em discussão sobre o conceito de comorbidade, Rutter (1994) assinalou que a correlação de dois ou mais problemas de comportamento pode refletir mecanismos causais compartilhados. Problemas como fracasso escolar, uso de substâncias, comportamentos sexuais de risco e atos delinqüentes estariam correlacionados uns com os outros. A sugestão da intercorrelação de diferentes tipos de problemas de comportamento conduzà idéia de um processo de base compartilhada, mesmo que tais problemas sejam topograficamente diferentes.

Nesse sentido, é importante considerar o modelo do Oregon Social Learning Center (OSLC), desenvolvido pelo grupo de Patterson, Reid, Dishion e Thoms (1992).
Esses autores, baseados em pesquisas com seguimentos de 20 anos, postulam que as interações de coerção na infância conduzem à anti-sociabilidade posterior. A hipótese fundamental foi de que os atos coercitivos aparentemente triviais, observados no lar e na escola, são os protótipos de comportamentos delinqüentes na adolescência. O estudo demonstra uma covariância significativa entre observações de eventos coercitivos (choramingar, chorar, gritar, bater ou ter acessos de raiva) e formas mais extremas de comportamento anti-social (cabular aula, brigar, usar drogas e roubar), e explica como os eventos anti-sociais relativamente triviais embutidos na interação social poderiam, eventualmente, levar a eventos de grande amplitude, mas baixa freqüência, tais como assalto ou uso de drogas.

O modelo de coerção (Patterson et al., 1992) enfoca as mudanças que ocorrem através do tempo e descreve uma seqüência de estágios de desenvolvimento que caracterizam a trajetória de comportamento desviante.

No primeiro estágio, os pais normalmente descrevem os anos pré-escolares do filho como difíceis e mencionam a sensível diferença dos irmãos e irmãs. Intitula-se esse marco do desenvolvimento de treinamento básico. A hipótese principal é que o treinamento básico para padrões de comportamento anti-social anteriores à adolescência tem lugar em casa, e os membros da família são os primeiros treinadores. Começa com o colapso da eficácia dos pais em confrontos disciplinares. Tal colapso permite o aumento da troca coercitiva entre a criança em questão e todos os outros membros da família. A criança acha que comportamentos aversivos como choramingar, chorar, gritar, bater ou ter acessos de raiva são eficazes, pois através deles consegue eliminar o comportamento aversivo de seus pais (pedidos para obediência, tarefas ou responsabilidades).

O segundo estágio é estabelecido diante da evidência de que a criança não está adquirindo as habilidades escolares. A hipótese é de que o comportamento rude da criança conduz à rejeição pelo grupo e aos déficits escolares. Os fracassos da criança no estágio dois limitam as experiências sociais disponíveis, e ela começa a procurar um ambiente receptivo, colocando-se em risco de envolvimento com um grupo desviante e de aprimoramento de suas habilidades anti-sociais, que é o terceiro estágio. Cada pequeno passo aumenta o risco da criança fracassar, no 
futuro, em áreas fundamentais relativas ao trabalho e às relações humanas, por exemplo. Acredita-se que o resultado dessa trajetória seja o adulto anti-social (Patterson et al., 1992; Syder \& Stoolmiller, 2002).

É difícil monitorar uma criança extremamente coercitiva, pois ela coage os membros da família a dar-lhe tempo extra na rua, sem supervisão, o que a leva ao grupo desviante. A resposta coercitiva ganha força, pois afasta o comportamento aversivo dos adultos, tais como pedidos para obediência e responsabilidades. As crianças dessas famílias estão, na maioria, sob risco de prisão já no começo da adolescência (Patterson, Dishion \&Yoerger, 2000).

Quando o comportamento de uma criança não é mais monitorado pelos pais e professores, está estabelecido o estágio de aprendizagem para atos clandestinos, tais como roubar, mentir, cabular aulas e usar drogas. O fracasso escolar recorrente e a rejeição pelos pais, professores e colegas convencionais induzem as crianças inábeis a buscarem colegas que sejam imagens refletidas delas mesmas. São crianças tristes e com pouca habilidade escolar, esportiva e social. Por volta dos doze ou treze anos, os pais e professores podem prontamente identificar quais grupos de crianças são desviantes (Patterson et al., 1992; Syder \& Stoolmiller, 2002).

Os dados brasileiros disponíveis também sugerem a presença de dificuldades escolares no histórico de abusuários ou dependentes de drogas. O IV Levantamento Nacional sobre Uso de Drogas entre Estudantes revelou, em todas as capitais pesquisadas, defasagem entre a série e a idade para os usuários de drogas, exceto álcool e tabaco. Em Curitiba, o atraso escolar representou 52,7\% da amostra de estudantes, como um todo (Galduróz, Noto \& Carlini, 1997).

Portanto, a presente pesquisa preocupou-se com aspectos do desenvolvimento escolar de adolescentes que adquiriram comportamento de abuso de substâncias psicoativas. Consideraram-se o grau formal de escolaridade dos adolescentes e suas percepções sobre seu desempenho na escola. A oportunidade de avaliar informações contidas em autobiografias realizadas em um contexto de tratamento se reveste de especial importância pela razão de disponibilizar relatos escritos obtidos diretamente dos envolvidos sobre a complexa dinâmica do uso de substâncias psicoativas e suas percepções em relação à trajetória escolar. Diferenças quanto ao gênero foram enfocadas.

\section{Método}

A primeira etapa desta pesquisa envolveu um contato junto ao representante oficial da instituição para encaminhamento do projeto. Após avaliação da comissão de ética, obteve-se autorização escrita para a realização da pesquisa.

O presente estudo foi desenvolvido a partir de pesquisa documental em autobiografias contidas em prontuários de adolescentes submetidos a tratamento em regime de internação, por abuso e/ou dependência de drogas, em uma instituição na cidade de Curitiba. Constituiu-se em dissertação de mestrado apresentada e aceita pela Universidade Federal do Paraná (2002); portanto o presente manuscrito contempla parte da dissertação "Análise de Auto-relatos de Adolescentes Usuários de Substâncias Psicoativas". O estudo estabeleceu um roteiro contendo nove categorias norteadoras, para, então, buscar os conteúdos e descrever os caminhos percorridos por adolescentes com problemas por uso de drogas. Uma das categorias estabelecidas previamente foi sobre a história escolar, que foi preenchida com todos os conteúdos, escritos pelos adolescentes, referentes às suas experiências escolares, gerando o tema deste presente artigo.

A autobiografia foi redigida durante a internação, após o recebimento de um guia com itens sugerindo uma seqüência no desenvolvimento do texto. São itens que se se referem à identificação pessoal, infância, história escolar, relacionamento com familiares e outras pessoas com quem tem interação, adolescência, consumo de drogas, comportamentos e conseqüências relacionadas ao consumo e histórico de tratamentos.

Este estudo se caracterizou como descritivo, compreensivo ou interpretativo, que é uma das formas da pesquisa qualitativa. A análise qualitativa preocupa-se com o significado dos fenômenos e processos sociais, levando em consideração as motivações, crenças e valores que permeiam a rede de relações sociais, procurando entender aquilo que está por trás das palavras sobre as quais se debruça, sendo o método indicado quando a necessidade é a apreensão da dinâmica de um processo (Bardin, 1997; Pádua, 1997). 


\section{Procedimentos}

Procedeu-se à busca de prontuários de pacientes que foram internados com idades entre onze e vinte e um anos, período considerado pela Organização Mundial de Saúde (Scivoletto, Tsuji, Abdo, Queiroz, Andrade \& Gattaz, 1997) como adolescência. Detectou-se que 23 moças chegaram para tratamento contra 137 rapazes. Estavam disponíveis, nos prontuários, treze autobiografias femininas e 95 masculinas. Para a análise dos dados foram utilizadas todas as treze autobiografias femininas; entre as masculinas foram sorteadas quinze para melhor equilíbrio e pareamento entre os dois grupos.

Foi construída uma matriz de dupla entrada, tendo na abscissa as nove categorias norteadoras e na ordenada os sujeitos (as autobiografias). A matriz foi preenchida pelas frases das autobiografias que correspondiam às categorias norteadoras.

Após a organização dos assuntos, nas respectivas categorias, os dados ficaram disponíveis para a leitura do conjunto de afirmativas. A leitura do conjunto de afirmativas teve o objetivo de identificar as frases-chave para cada categoria norteadora. Essas frases-chave foram obtidas através da seleção literal de trechos de cada autobiografia. Garantiu-se, dessa forma, que a essência da resposta relacionada a cada categoria norteadora ficasse preservada para análise; portanto as frases-chave expressaram fielmente o relato escrito dos adolescentes pesquisados. Em seguida procedeu-se à identificação de subcategorias (escritas na forma de palavra, conceito ou expressão) que representassem uma síntese das frases-chave. Essas subcategorias indicaram o que as frases-chave tinham de essencial, o que elas, em suma, queriam dizer. Foram registradas ao lado de cada subcategoria as freqüências de repetição por autobiografia. O procedimento foi realizado em i⿱乛龰 separado para o grupo das autobiografias dos rapazes e para o grupo de autobiografias das moças, para posterior comparação.

Para o presente estudo selecionou-se a categoria história escolar. Quanto a análise de dados e apresentação dos resultados, a partir das frases-chave elencadas em cada categoria norteadora, e considerando-se as subcategorias, foram construídos textos que serviram para ilustrar o conjunto temático de cada subcategoria. Esse texto contém as principais idéias obtidas dos conteúdos das autobiografias e foi denominado discurso-síntese. No decorrer da apresentação dos resultados e discussão faz-se uso de alguns discursos-síntese, uma vez que a reprodução de todos é desnecessária e tornaria a leitura extenuante. Paralelamente foram construídas tabelas com as subcategorias de cada categoria norteadora e suas respectivas freqüências. Utilizaram-se dados de identificação para o levantamento de um perfil sociodemográfico.

\section{Resultados e Discussão}

\section{Perfil sociodemográfico}

Como exposto na seção de método e procedimento, procedeu-se à seleção de prontuários com autobiografias e foi verificado que 137 eram de adolescentes masculinos e 23 de adolescentes femininas. Ocorreu um nítido predomínio de adolescentes masculinos que chegaram para tratamento, apesar de ser conhecido atualmente na literatura que as moças atingem porcentagem de uso de drogas semelhante aos rapazes. Galduróz, Noto e Carlini (1997) demonstraram que, entre estudantes, a proporção de usuários do sexo masculino é semelhante à do sexo feminino, 26,8\% e 22,9\%, respectivamente. Entretanto, a demanda para tratamento foi bem menor entre as adolescentes femininas, neste e em outros estudos (Scivoletto et al., 1999), existindo a necessidade de se conhecer melhor tanto as conseqüências do uso como as motivações para tratamento que provavelmente são diferentes entre os gêneros.

Observou-se que os adolescentes estudados chegaram para internamento a partir dos catorze anos de idade, não sendo encontrado, entre todos os prontuários de adolescentes da instituição, idade inferior a catorze anos. Verificou-se maior concentração de chegada para internamento entre as idades de 17 e 20 anos (Figura 1). Adolescentes internados por problemas relacionados ao uso de álcool e drogas entre 17 e 20 anos de idade, supostamente, experimentaram drogas psicoativas em idades mais precoces. Alves e Kossobudzki (2002) estudaram 682 adolescentes internados em Curitiba por uso de álcool e drogas. Encontraram maior concentração de internamento entre 15 e 17 anos. Uma possível diferença entre as amostras, além do número de participantes, seria o objetivo do 
presente estudo em analisar as histórias dos jovens através das suas autobiografias. Portanto, o critério para seleção dos prontuários foi o de conter a autobiografia, podendo contribuir para essa diferença quanto à idade no internamento.

Hipoteticamente, dentro do desenvolvimento escolar no Brasil, o presente grupo deveria contar com 19 adolescentes com o segundo grau completo, já que 19 deles são maiores de 18 anos. No entanto, encontrou-se que dez adolescentes apenas alcançaram esse grau escolar (Tabela 1). Dois terços dos rapazes (10) tiveram, ao menos, duas reprovações na escola, e um terço deles (5) relatou, além de reprovação, a expulsão da escola. As moças mostraram um perfil escolar diferente dos rapazes, como maior escolaridade, menos reprovações e nenhuma expulsão da escola. As dificuldades escolares apresentadas pelos adolescentes são significativas no que diz respeito à importante função do desempenho escolar. Ser bem-sucedido na escola envolve fatores cruciais na adolescência, como auto-estima, senso de auto-eficácia, aceitação pelos pares bem-sucedidos e pelos professores, além do próprio desenvolvimento intelectual e cognitivo. A baixa escolaridade é um fator que tem demonstrado forte associação com consumo de drogas em outros achados da literatura (Patterson et al., 1992; Nappo, Galduróz \& Notto, 1994; Scivoletto \& Morihisa, 2001). Dentre os 682 adolescentes curitibanos internados por uso de drogas, $63,4 \%$ da amostra registraram atraso escolar (Alves \& Kossobudzki, 2002).

\section{Análise qualitativa das autobiografias}

Um importante marcador comportamental da infância e da adolescência refere-se às habilidades na escola. Para tanto, buscou-se nas autobiografias o que os adolescentes aqui estudados descreveram sobre suas facilidades e dificuldades no comportamento de estudo. Esse conteúdo originou a categoria história escolar com as suas subcategorias (Quadro 1).

A categoria que enfocou a história escolar merece atenção em dois pontos principais. Primeiro, catorze rapazes relataram dificuldades precoces na aquisição do desempenho escolar e destacaram ou baixo engajamento em comportamento de estudo (subcategoria: Eu não gostava de estudar, achava muito

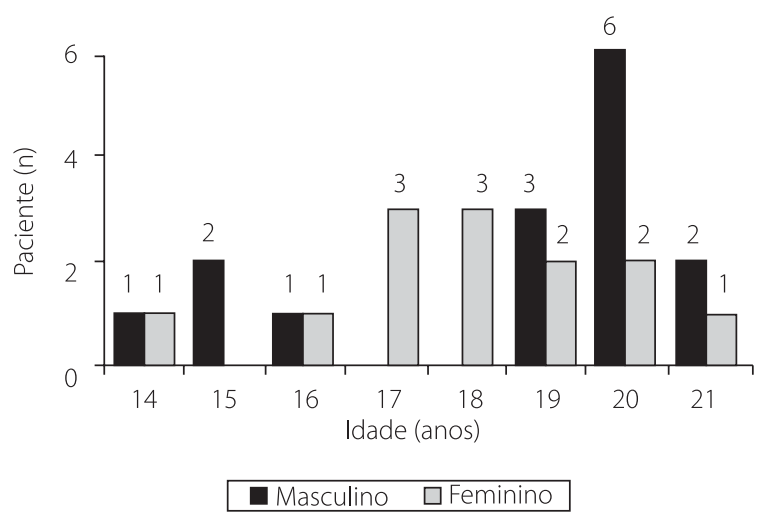

Figura 1. Idade dos adolescentes internados por uso de álcoole outras drogas.

Tabela 1. Escolaridade dos adolescentes internados por uso de substâncias.

\begin{tabular}{lccc}
\hline Escolaridade & $\begin{array}{c}\text { Masculino } \\
(\mathrm{n}=15)\end{array}$ & $\begin{array}{c}\text { Feminino } \\
(\mathrm{n}=13)\end{array}$ & $\begin{array}{c}\text { Total } \\
(\mathrm{n}=28)\end{array}$ \\
\hline 10 grau incompleto & 2 & - & 2 \\
10 grau completo & 4 & - & 4 \\
20 grau incompleto $^{\circ}$ & 4 & 8 & 12 \\
20 grau completo $^{\circ}$ grau incompleto & 3 & 1 & 4 \\
\hline Reprovação & 2 & 4 & 6 \\
Expulsão & 10 & 5 & 15 \\
\hline
\end{tabular}

difícil) ou dificuldade disciplinar e comportamental (subcategoria: Meu comportamento era péssimo, eu não conseguia parar).

O segundo ponto merecedor de atenção foi o bom desempenho escolar relatado pelas moças usuárias de drogas, o que diferenciou o desenvolvimento delas em relação ao dos rapazes deste estudo. Sete moças relataram terem sido ótimas alunas, e quatro tiveram boas notas até o início da puberdade, diferentemente dos meninos: um entre os 15 declarou bom desempenho escolar na infância. Três discursos-síntese apresentados a seguir ilustram as características e especificidades dos gêneros.

Eu não gostava muito de estudar. Meu rendimento escolarnão era dos melhores. Minha evolução escolarfoi muito restrita... sempre tive dificuldades nos estudos, nunca fuidestaque... Achava aquilo muito difícil. Estudei pouco porque não gostava... de estudar eu não gostava, fiquei com o mesmo caderno por três anos. (Discurso- 
-síntese de adolescentes masculinos usuários de drogas, subcategoria: Eu não gostava de estudar, achava muito difícil).

No préeujá era chamado de furacão... nunca fuibem em comportamento. Não conseguia parar... não prestava atenção eera muito indisciplinado. Meu comportamento era péssimo... ou tava brigando ou botando lenha... . Aos 7 anos eu era um dos três mais briguentos da sala. Sempre houve problemas ena $5^{a}$ eu fui expulso daquele colégio... fuiexpulso 4 vezes.... (Discurso-síntese das autobiografias dos adolescentes masculinos usuários de drogas, subcategoria:Meu comportamento era péssimo, eu não conseguia parar).

Eu era uma ótima aluna, na 5 a série fui para o fundão e daí minhas notas começaram a despencar. Gostava muito de estudar, me interessava pela... matérias, comecei a ter problemas de disciplina na 7a série, daí eu reprovei. Tive um ótimo desempenho escolar até a $6^{a}$ série. Em tudo que eu fazia eu era a melhor, na ba série eu comecei a mudar, me desinteressando pelo colégio. Nuncatinhatido problemas no colégio, fui vice-campeã brasileira em...e campeã estadual antes dos 14 anos... eu era a primeira da classe." (Discurso-sintese das autobiografias de adolescentes femininas usuárias de drogas, subcategoria Tive um ótimo desempenho escolar, até a $6^{a}$ ou 7a série).

A adaptação da criança ao ambiente escolar e aos pares é o primeiro desafio para o ajustamento fora da família. No presente estudo constatou-se que os rapazes não apresentaram uma adequada adaptação na escola. Ao contrário, as dificuldades escolares foram precoces, encontrando acordo com a perspectiva que correlaciona características de temperamento da criança desde a educação infantil e ensino fundamental com o desempenho acadêmico e adaptação ao ambiente escolar. Nessa perspectiva as crianças mal adaptadas estão em risco para experimentarem discriminação e rejeição por parte dos professores e pares, podendo definitivamente abandonar a escola. Esses fatores contribuem para o potencial de comportamentos e psicopatologias associados ao abuso de álcool e drogas (Bahls \& Ingberman, 2002; Patterson et al., 1992).

Quanto ao desenvolvimento escolar descrito pelos adolescentes, verificou-se que os rapazes, mais do que as moças, apresentaram dificuldades na aquisição de habilidades escolares. Tal condição aponta para a importância do enfoque preventivo e específico com crianças, uma vez que dificuldades precoces, tais como o baixo desempenho, prenunciam dificuldades futuras. Rutter (1980) sugeriu que experiências positivas são relacionadas com resiliência, e ter sucesso na escola pode prevenir o desenvolvimento de transtornos psiquiátricos entre as crianças. As que exibem maior grau de resiliência são aquelas que apresentam maior aspiração educacional. Kandel e Davies (1992) reportaram que o melhor desempenho escolar em préadolescentes diminuiu o envolvimento em atividades desviantes, incluindo o uso de drogas.

Clayton (1993), em considerações sobre fatores de risco na escola, pontua que o senso de autovalor das pessoas jovens é freqüentemente frágil e isso certamente varia em termos da percepção do desempenho. Existem muitas oportunidades dentro do contexto escolar para o alcance de um senso de autovalor e desempenho. Ser aceito por professores e

Quadro 1. Subcategorias provenientes das 28 autobiografias de adolescentes do sexo masculino e feminino internados pelo uso de substâncias psicoativas, em relação à categoria: história escolar.

\begin{tabular}{|c|c|}
\hline Autobiografias & Adolescentes \\
\hline Subcategorias & Freqüência \\
\hline \multicolumn{2}{|l|}{ Maculino $(n=15)$} \\
\hline Eu não gostava de estudar, achava muito difícil & 7 \\
\hline Até a 5 a série tive um bom desempenho escolar & 1 \\
\hline Meu comportamento era péssimo, eu não conseguia parar & 7 \\
\hline \multicolumn{2}{|l|}{ Feminino $(n=13)$} \\
\hline Nunca fui muito fã de estudar & 2 \\
\hline Tive um ótimo desempenho escolar, até a 6a ou 7a série & 7 \\
\hline Sempre gostei de estudar e tive boas notas & 3 \\
\hline Minha vida escolar foi tumultuada, devido às brigas, mas sempre com boas notas & 1 \\
\hline Total geral & 28 \\
\hline
\end{tabular}


colegas é muitas vezes percebido pela criança e pelo adolescente quase que como uma questão de"vida ou morte", escreve de modo metafórico o autor.

Quanto às moças, chama-se a atenção para o fato de os relatos descreverem uma ruptura na puberdade: elas perceberam problemas de disciplina, desinteresse por estudar e queda nas notas. Nesse período, descreveram, também, associação com colegas "do fundão da sala de aula", com os que cabulavam ou com os que usavam alguma substância. Nessa fase ocorreu o início do uso de substâncias e atos antisociais, diferentemente dos rapazes que descreveram problemas dessa natureza de modo mais continuado desde a infância. Os achados de Kumpulainen e Roine (2002) enfatizaram que em meninas os sintomas prévios (doze anos) ao uso pesado de álcool (quinze anos) não foram aqueles de efeito depressivo, mas aqueles relatados sobre falha no desempenho escolar e baixa auto-estima. Nos meninos os sintomas prévios se relacionaram a problemas interpessoais com tendências agressivas. Kumpulainem (2000) também encontrou, em outro estudo de seguimento, que problemas de conduta ou externalizantes predisseram uso pesado de álcool em meninos.

A descrição realizada pelas moças deste estudo sobre o bom desempenho escolar na infância e uma ruptura a partir da puberdade constitui-se um achado importante e motivador para o desenvolvimento de futuras pesquisas que coloquem em perspectiva o desenvolvimento de problemas de comportamento e uso de drogas em meninas. Os estudos longitudinais e prospectivos enfocam mais os meninos e poucos estudos longitudinais enfocam as especificidades do gênero feminino (Pajer, 1998). Quando a literatura aborda adolescentes usuários de drogas é comum relacionar a defasagem escolar, porém, maior especificação quanto a possíveis diferenças entre os gêneros é encontrada em estudos com adultos, que relacionam maior escolaridade em mulheres do que em homens em dependentes de substâncias (Zilberman, Angélico, Hochfraf \& Andrade, 1994; Galduróz Noto \& Carlini, 1997; Gomberg, 1999).

Fergunsson e Woodward (2000) examinaram um grupo de 488 mulheres jovens e encontraram associação significante entre problemas de condutas no início da adolescência e dificuldades educacionais, abuso de substâncias, problemas de saúde mental e compor- tamento sexual de risco posteriormente na adolescência, como encontrado no presente estudo.

Em síntese, as adolescentes femininas do presente estudo relataram bom desempenho escolar até o início da puberdade, como já evidenciado. Elas perceberam e relataram uma mudança nessa fase da vida, ocorrendo desinteresse pelo estudo e problemas de disciplina de modo diferente aos rapazes, que desde muito cedo iniciaram uma trajetória escolar com dificuldades. As moças demonstraram uma capacidade escolar diferenciada. O grau de escolaridade das adolescentes femininas foi maior em relação ao dos rapazes, ocorreu menor índice de reprovação entre elas e não ocorreu relato sobre expulsão escolar entre as moças, provavelmente como resultado de seu maior desempenho escolar e menor taxa de problemas de comportamentos externalizantes até a puberdade. Existe um consenso na literatura que a síndrome de abuso de substâncias em mulheres é diferente do padrão reconhecido em homens (Glantz, 1992; Zilberman et al., 1994 Kumpulainem \& Roine, 2002), e os resultados aqui encontrados sugerem que sinais que provavelmente prenunciam o abuso de drogas na adolescência, como dificuldades escolares, também diferem em relação ao gênero.

\section{Conclusão}

As crianças que são privadas de experiências positivas e consistentes no ambiente familiar são as mais carentes de experiências reforçadoras ao chegarem na escola. Poderiam encontrar no ambiente escolar uma chance para o exercício da assertividade e do autovalor. É reconhecido, hoje, que os importantes conceitos dos vínculos precoces propostos por Bolwby e Ainsworth a partir da década de 1940/1950 (Herbert, 1989; Rutter, 1995) sobre as primeiras interações com a mãe não se restringem mais à imperativa vinculação do início da vida, oferecendo uma chance maior para que experiências tardias de recebimento de cuidado e reforçamento positivo possam apresentar um impacto. Tal propósito requer o investimento em qualificação de educadores e uma política educativa que possa lidar com os "alunos difíceis", que talvez sejam os que mais precisem de uma escola que não rejeite ou expulse, mas que enfrente o desafio. 
Nas 28 autobiografias estudadas, encontrou-se em apenas três delas, escritas por moças, referência a uma autopercepção positiva. Ressalte-se que o autoconceito positivo relatado pelas três moças conferiu ao bom desempenho escolar um papel chave: "Eu era estudiosa e inteligente".

\section{Referências}

Alves, R., \& Kossobudsky, A.L. (2002). Caracterização dos adolescentes internados por álcool e outras drogas na cidade de Curitiba. Interação em Psicologia, 6 (1), 65-79

Bahls, F.R.C., \& Ingberman, Y. (2002). Características de pais com filho usuário de drogas. Sessão pôster apresentado no XI encontro Brasileiro de Psicologia e Medicina Comportamental, Londrina, PR.

Bardin, L. (1997). Análise de conteúdo. Lisboa: Edições 70.

Clayton, R.R. (1993). Transitions in drug use: risk and protective factors. In M. Glantz \& R. Pickens (Eds.). Vulnerability to drug abuse (pp.15-53). Washington, DC: American Psychological Association.

Fergunsson, D.M., \& Woodward, L.J. (2000) Educational, psychosocial, and sexual outcomes of girls with problems in early adolescence. Journal of Child Psychology and Psychiatry, 46 (6), 779-792.

Galduróz, J.C.F, Noto, A.R, \& Carlini, E.A. (1997). IV Levantamento sobre o uso de drogas entre estudantes de $1{ }^{\circ}$ e $2^{\circ}$ graus em 10 capitais brasileiras. São Paulo: [CEBRID] Centro Brasileiro de Informações sobre Drogas Psicotrópicas.

Glantz, M.D. (1992). A developmental psychopathology model of drug abuse vulnerability. In M.D. Glantz \& R. Pickens (Eds.). Vulnerability to drug abuse (pp.389-419). Washington, DC: American Psychological Association.

Gomberg, E.S.L. (1999). Women. In B.S. McCrady \& E.E. Epstein (Eds.). Addictions: a comprehensive guidebook (pp.527-541). New York: Oxford University Press.

Herbert, M. (1989). Working with children and their families. In M. Herbert (Ed.). Responsiveness in parent and children (pp.93-108). Chicago: Lyceum Books.

Hops, H., Davis, B., \& Lewin, L.M. (1999). The development of alcohol and other substance use: a gender of family and peer context. Journal of Studies Alcohol Supplement, 13, 22-31.

Kandel, D.B., \& Davies, M. (1992). Progression to regular marijuana involvement: phenomelogy and risk factors for near-daily use. In: M. Glantz \& R. Pickens (Eds.). Vulnerability to drug abuse (pp.211-255). Washington, DC: American Psycological Association.

Kumpulainen, K. (2000). Psychiatric symptoms and deviance in early adolescence predict havy alcohol use 3 years later. Addiction, 95 (12), 1847-1857.
Kumpulainen, K., \& Roine. S. (2002). Depressive symptoms at age 12 years and future heavy alcohol use. Addictive Behaviors, 27 (3), 425-436.

Nappo, S., Galduróz, J.C.F., \& Noto, A.R. (1994). Uso do "crack" em São Paulo: fenômeno emergente? Rev ABP-APAL, 2 (16), 75-83.

National Institute on Drug Abuse. (1997). Preventing drug use among children and adolescent: a research-based guide (pp.2-7). Bethesda: National Institutes of Health. (NIH Publication No.99-4212).

Pádua, E.N.M. (1997). Metodologia de pesquisa. Abordagem teórico-prática (2. ed). Campinas: Papirus.

Pajer, K.A. (1998). What happens to "bad" girls? A review of the adult outcomes of antisocial adolescent girls. American Journal of Psychiatry, 155 (7), 862-870.

Patterson, G.R., Reid, J.B., Dishion, T.J., \& Thoms, G.A. (1992). Antisocial boys. Eugene, OR: Castalia Publishing.

Patterson, G.R., Dishion, T.J., \& Yoerger, K. (2000). Adolescent growth in new forms of problem behavior: macro and micro-peer dynamics. Prevention Science, 1 (1), 3-12.

Rutter, M. (1980). Emotional development. In: M. Rutter (Ed.). Developmental Psychiatry (pp.306-322). Washington, DC: American Psychiatric Press.

Rutter, M. (1994). Comorbidity: meanings and mechanisms. Clinical Psychology: Science and Practice, 1, 100-103

Rutter, M. (1995). Clinical implications of attachment concepts: retrospect and prospect. Journal of Child Psychoology Psychiatry, 56 (4), 549-571.

Scivoletto, S., Henriques, S.G.H., \& Andrade, A.G. (1997). Uso de drogas por adolescentes que buscam atendimento ambulatorial: comparação entre "crack" e outras drogas ilícitas - um estudo piloto. Rev ABP-APAL, 19 (1), 7-17.

Scivoletto, S., Tsuji, R.K., Abdo, C.H.N., Queiroz, S., Andrade, A.G., \& Gattaz, W.F. (1999). Relação entre consumo de drogas e comportamento sexual de estudantes de $2^{\circ}$ grau de São Paulo. Revista Brasileira de Psiquiatria, 21 (2), 87-94.

Scivoletto, S., \& Morihisa, R.S. (2001). Conceitos básicos em dependência de álcool e outras drogas na adolescência. J Bras Dep Quím, (supl 1), 30-33.

Syder, J., \& Stoolmiller M. (2002). Reinforcement and coercion mechanisms in the development antisocial behavior: the family. In J.B. Reid, G.R. Patterson \& J. Snyder (Eds.). Antisocial behavior in children and adolescent: a developmental analysis an model (pp. 63-100). Washington, DC: Americam Psychological Association.

Zilberman, M.L., Angélico-Júnior, F.V., Hochgraf, P.B., \& Andrade, A.G. (1994). Mulheres e homens com dependência de drogas: comparação clínica e demográfica em tratamento ambulatorial. RevABP-APAL, 16 (3), 105-112.

Recebido para publicação em 11 de abril e aceito em 30 de junho de 2005. 